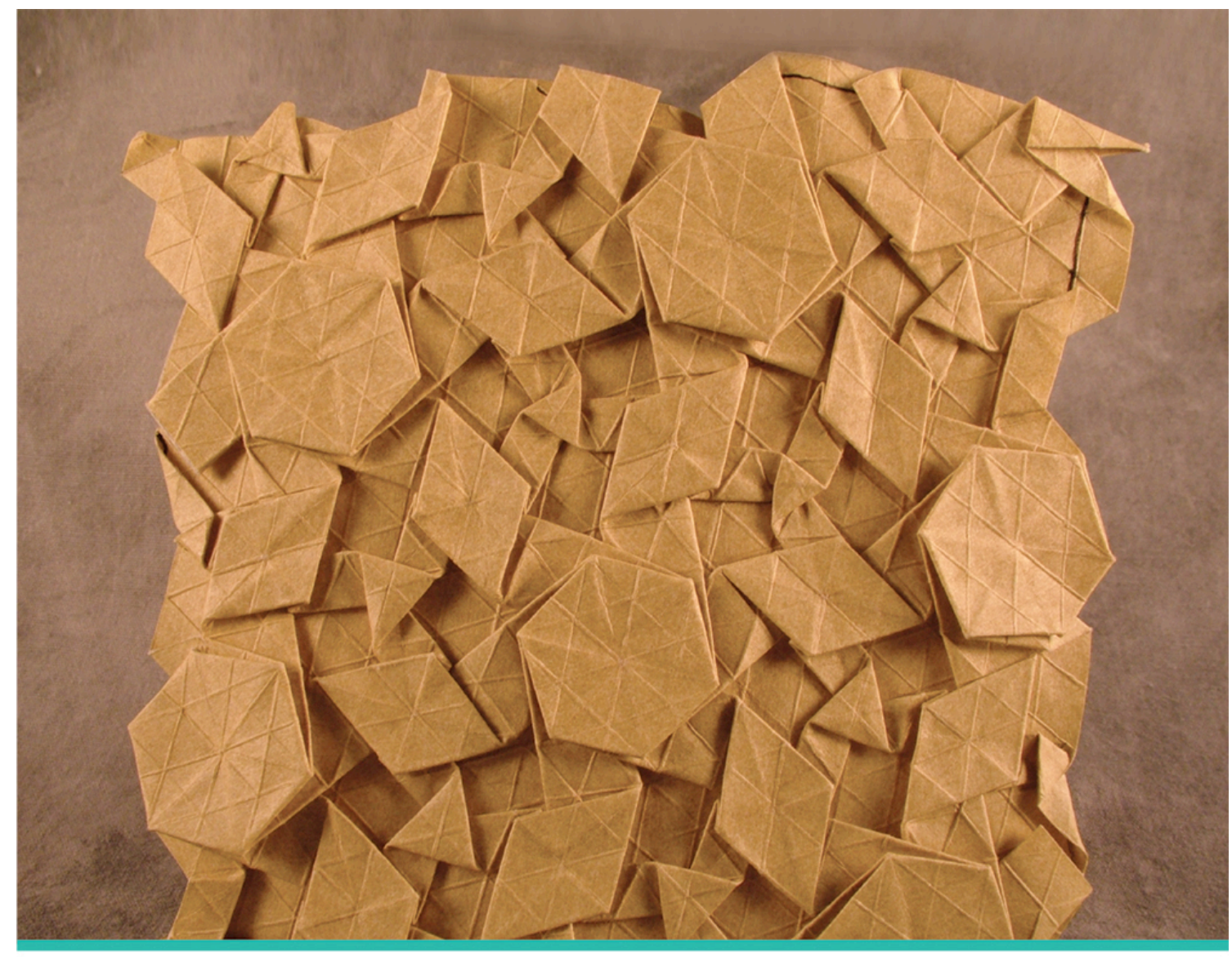

\title{
Open Development
}

Networked Innovations in International Development

edited by Matthew L. Smith and Katherine M. A. Reilly foreword by Yochai Benkler

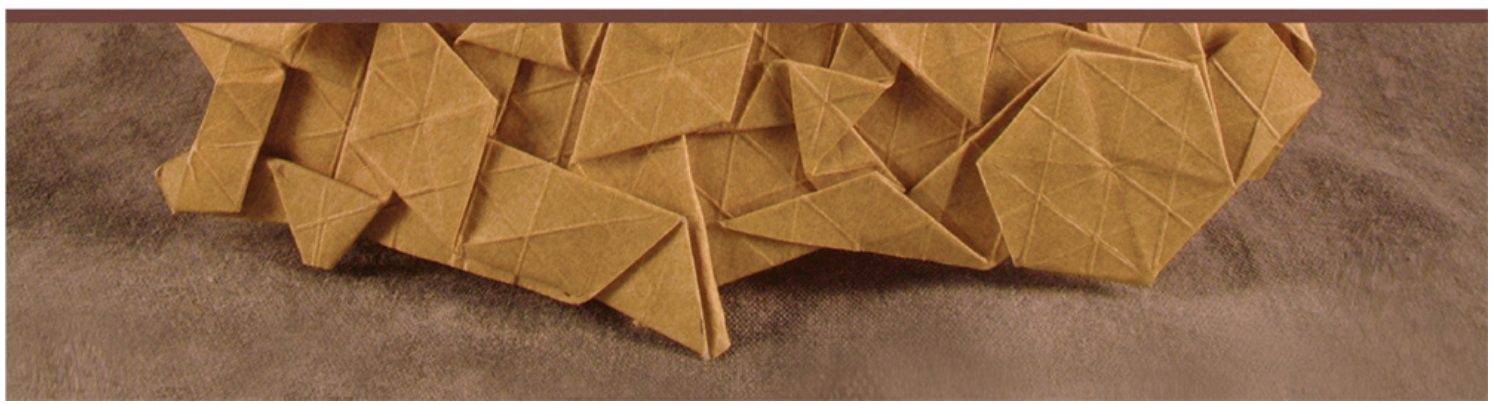




\section{(c) 2013 International Development Research Centre and Contributors}

This work is licensed under a Creative Commons Attribution 4.0 (CC-BY 4.0) International License.

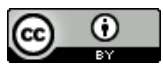

Published by the MIT Press. MIT Press books may be purchased at special quantity discounts for business or sales promotional use. For information, please email special_sales@mitpress.mit.edu.

A copublication with

International Development Research Centre

PO Box 8500

Ottawa, ON K1G 3H9

Canada

www.idrc.ca / info@idrc.ca

ISBN 978-1-55250-568-7 (IDRC e-book)

This book was set in Stone Serif and Stone Sans by the MIT Press. Printed and bound in the United States of America.

Library of Congress Cataloging-in-Publication Data

Open development : networked innovations in international development / edited by Matthew L. Smith, and Katherine M.A. Reilly ; foreword by Yochai Benkler.

pages $\mathrm{cm}$

Includes bibliographical references and index.

ISBN 978-0-262-52541-1 (pbk. : alk. paper) 1. Information technology-Developing countries. 2. Economic development-Developing countries. 3. Social networksDeveloping countries. I. Smith, Matthew L. editor of compilation. II. Reilly, Katherine M. A., 1974- editor of compilation.

HC59.72.I55O64 2014

$303.48 ' 33091724-\mathrm{dc} 23$

2013016541

$\begin{array}{lllllllll}10 & 9 & 8 & 7 & 6 & 5 & 4 & 3 & 2\end{array}$ 


\title{
8 Centering the Knowledge Peripheries through Open Access: Implications for Future Research and Discourse on Knowledge for Development
}

\author{
Leslie Chan and Eve Gray
}

Open Access (OA), or free online access, to scholarly and scientific publications has emerged as a significant global movement since the twenty-first century began. ${ }^{1}$ OA has also become an area of special interest to the development community, given that access to knowledge is fundamental to all aspects of human development, from health to food security, and from education to social capacity building. The potential of OA to dramatically improve the visibility, usage and, therefore, the impact of publicly funded research is also increasingly recognized by national and international funding bodies, aid agencies, and institutions of higher learning. This has led to the implementation of a growing number of policy mandates that ensure public accessibility to publicly funded research. ${ }^{2}$

Open Access has the potential to facilitate the flow of knowledge in all directions, not only from the Global North to the Global South, but also from the Global South to the Global South, which is far more essential for local and development since Global Southern countries have more in common than with those of the Global North. ${ }^{3}$ This at a time in which there are increasing calls by policymakers, particularly in the Global South, for research to demonstrate its impact on the United Nation's Millennium Development Goals. For example, the Namibian prime minister asked of a UNESCO conference in 2010: "How could the application of knowledge end poverty and hunger in Africa? How could higher education empower women and promote gender equity? How can knowledge be considered in an African context to address child mortality and improve maternal health?" ${ }^{4}$ This chapter, however, argues that, as OA is currently practiced, its potential to advance development is not being exploited.

Instead of being used to support greater local participation in research that would confront fundamental development issues, OA is all too often focused on improving online access to journal articles, particularly those 
in expensive Global Northern journals. This is in good part because of the near universal adoption-even in the developing world-of the Thomson Reuter's Science Citation Index and Journal Impact Factor ${ }^{5}$ (JIF) as a measure of journal quality and international prestige.

Drawing largely on African examples, this paper seeks to demonstrate how the use of this narrow global yardstick as a one-size-fits-all framework has resulted in the continual invisibility of research publications from the Global South and distortion of research priorities and agendas in many developing countries. ${ }^{6}$ The adherence to this approach by developing country governments has led to a situation where research that is of vital importance to national development priorities has been marginalized in the race for improved citation metrics. This applies also to a volume of development-focused publications produced in developing countries that remain invisible as a result of such policies. ${ }^{7}$

Implicit in the acceptance of the JIF as the standard measure for publication impact is an industrial age "innovation system" view that seeks to measure the potential impact of research in terms of commercial exploitation for economic growth. ${ }^{8}$ In this discourse there is a particular understanding of what constitutes the center or mainstream research, from which voices and knowledge from the Global South-dismissed as "local knowledge" - are largely excluded and within which different disciplines are valued unequally. This is in contrast to the twenty-first-century network society described by Yochai Benkler, ${ }^{9}$ in which a decentered and cooperative environment can lead to different innovation approaches, more likely to contribute to development goals.

This chapter will argue that while OA provides the means to challenge the hegemony of this global publishing system, there is a need to rethink what constitutes scholarly publication, quality, and impact in an open networked knowledge environment. To do so requires the inclusion of a wider range of research objects or outputs and the development of an expanded system of accounting for the social and development impact of research. ${ }^{10}$ Such a system would include alternative and enhanced metrics that take into account the multiple outcomes of improved access beyond citation impact, and into less tangible realms including expanded collaboration, inclusive participation, cross disciplinary exchange of ideas, and uptake of research knowledge by development workers and policymakers. Such a system would also provide alternative foundations for allocating research funding that would better recognize the role of publicly funded research institutions in developing countries. 


\section{The Geo-Politics of Academic Knowledge Production}

Since the mid-1950s, knowledge and knowledge management have come to be seen as key drivers of development. Although this has often been expressed as a matter of economic growth, in recent decades there has been increasing emphasis on the importance of knowledge dissemination and information provision for human and social development. As Benkler argues, "In the global networked information economy, the constituent elements of human welfare and development depend on information and knowledge."11 These sentiments are echoed in a number of global and regional policy statements from UNESCO and the World Bank, ${ }^{12}$ to continental initiatives such as the African Union Plan of Action for Renewing the African University. ${ }^{13}$ This is true also for the universities, where the research they disseminate is often seen as lying at the heart of any sustainable effort to build economic growth and foster human development, especially in developing countries.

There seems, however, to be a blockage between these policy ideals and the creation of an effective regime for knowledge dissemination to underpin these development targets. Benkler's analysis of the rise of the information society offers some insights into this situation. He argues that there have been conflicting views on the best way knowledge can be made to contribute to the economy and society. These views are reflected in four sequential but overlapping events: (1) the rise of a neoliberal trading system; (2) the rise of an information economy enshrined in global treaties for intellectual property; (3) the rise of a network society in which the production of culture has been radically decentralized; and (4) the linking of human rights and development as freedom in the face of an inequitable global dispensation. ${ }^{14}$

Ideas about how knowledge can contribute to development will be very different depending on whether they are inspired by the trade related aspects of intellectual property rights (TRIPS), and a TRIPS-governed information economy, or an understanding of the radically decentralized and collaborative network society. ${ }^{15}$ The conflation of these two very different development paradigms in global and national research policy creates a similar disjuncture between our understanding of the importance of knowledge for development and the creation of effective policy for the leverage of research for its contribution to the public good.

What has happened, Benkler argues, is that access to knowledge has become essential to developing countries at the same time as the enforcement of control over information flows became of central concern to the 
major copyright industries, using maximalist models of intellectual property (IP) enforcement and the leverage of trade treaties such as TRIPS. ${ }^{16}$ In this contested terrain, developing countries recognize the importance of knowledge for development, but allow commercial publishing values to influence the policies that drive knowledge and educational systems. ${ }^{17}$

Thus UNESCO's report, Toward Knowledge Societies, published in 2005, recognized the value of open access initiatives like the Public Library of Science (PLOS) and http://ArXiv.org, but it recommended donor-funded collaborations with commercial providers, such as those evidenced in the reduced-subscription medical and agricultural journal initiatives HINARI and AGORA, as a means to redress global inequality in access to knowledge. The emphasis is thus on greater distribution of commercially produced centralized resources from the Global North over models that favor decentralized production, collaboration, and distribution of knowledge from the Global South. There is little sense in the 2005 report that research might emerge from countries in the Global South; rather, the emphasis falls on enhanced North-South access to (and consumption of) Global Northern knowledge.

The UNESCO Science Report 2010 continues the endorsement of counts of journal articles and patents as a core measure for judging the effectiveness of national research systems. ${ }^{18}$ This is a system that is now deeply entrenched in the academy, ${ }^{19}$ which we argue is at odds with the development potential offered by the twenty-first-century networked knowledge society, running counter to policymakers' desire to achieve social and economic impact from research. It is in the UNESCO Social Science Report 2010, interestingly in a more marginalized disciplinary research area, that more complex arguments emerge in favor of a changed evaluation system and a wider range of publications. ${ }^{20}$

\section{The Center and the Periphery According to ISI/Thompson Reuters}

In A Geopolitics of Academic Writing, A. Suresh Canagarajah ${ }^{21}$ shows how scholarship from the center has created publication conventions and practices that are simultaneously shaped by technological progress and social institutions. Scholars operating in the peripheries have to adopt these discursive practices in order to gain entry into the center, where mainstream knowledge resides. This system of production has been perpetuating itself without reflection. Voices and knowledge from the Global South that do not fit international standards for publishing are excluded from the wellknown and largely commercial databases and their citation counts, and so they remain largely invisible. 
Even as the Internet has opened new channels for collaboration and dissemination, the journal article has remained the currency of scholarly recognition across the English-speaking world and beyond. In this system, the journals that qualify for inclusion in the indexes are predominantly the publications of large commercial publishing companies based in the Global North. In 2004, four top countries produced 84 percent of the articles in the dominant index, the Institute for Scientific Information (ISI) index, while at the other end of the spectrum, 163 countries contributed 2.5 percent of the indexed articles. ${ }^{22}$

Even after a review of the role of developing country journals in the ISI Web of Science in 2008-which responded to a rising tide of criticism of bias inherent in the indexes and resulted in seven hundred developing country journals being added to the indexes-Africa remained poorly represented. Nineteen journals were added from South Africa, in addition to one from Kenya and one from Nigeria. To put this in perspective, in 2007 there were twenty-eight African journals in the index out of a total listing of around ten thousand according to the Institute for Scientific Information (ISI) report compiled in 2010. More significantly, the criteria for this expanded inclusion of developing country journals remained the extent to which articles in these journals could contribute to global understanding of science from the periphery. ${ }^{23}$

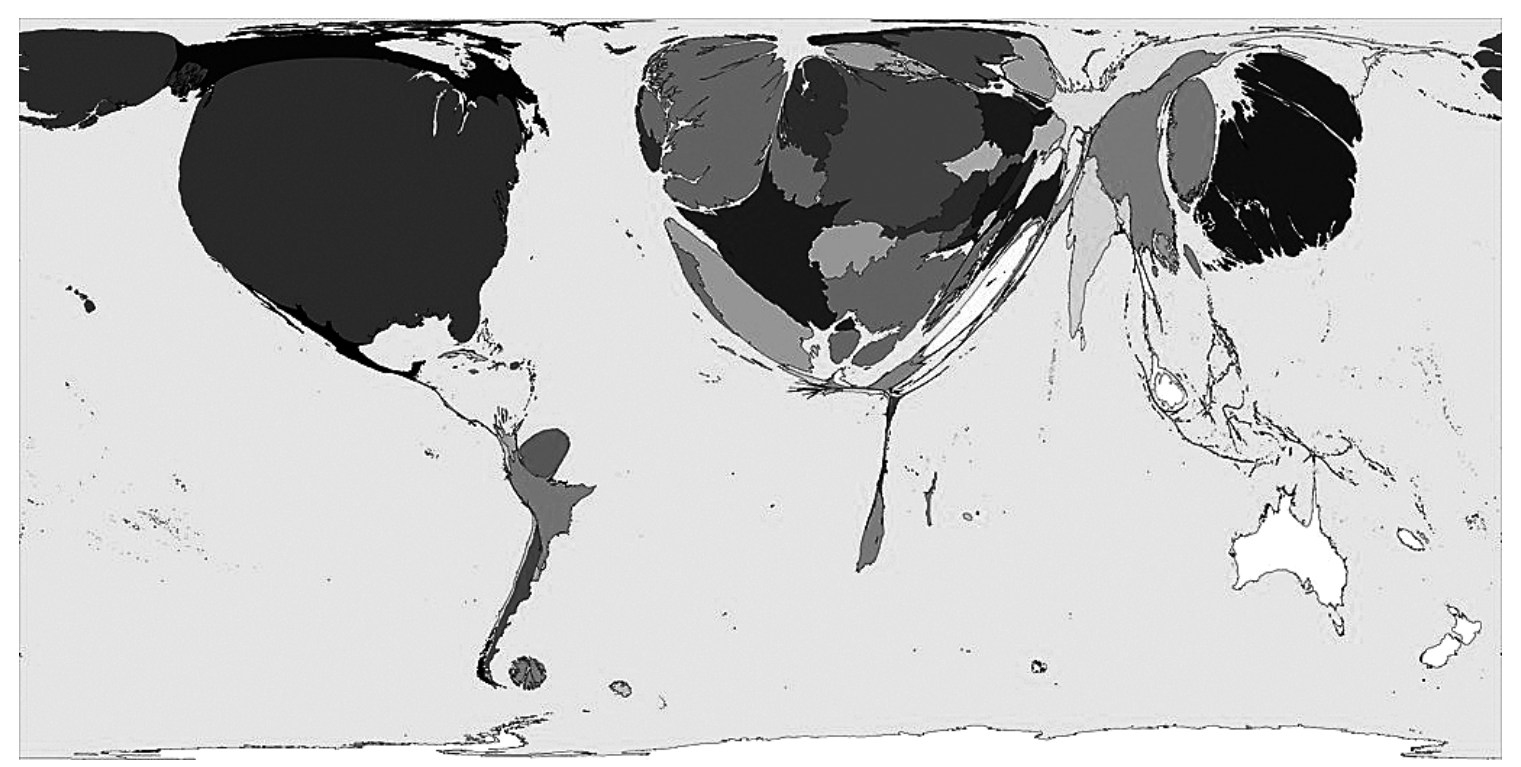

Figure 8.1

The map shows the unequal contribution and participation in journal publishing science. Source: World Bank's 2005 World Development Indicators. 
Thus, it is not a coincidence that the centers of this global publishing system reside primarily in the Global North, dominated by the United States and the United Kingdom in particular, with Japan being the notable exception from Asia. Figure 8.1 depicts the world of knowledge production according to Thomson's Science Citation Index. ${ }^{24}$

This would matter less if the ISI indexes had not been accepted by developing countries as the measure of scholarly excellence, as countries, even in the developing world, compete for their position in the global university rankings, such as the Times Higher Education (THE) rankings, as the primary measure of success.

These rankings are, in turn, tied to measures of overall development of a country or an entire region. So, for example, the Global Research Report Africa produced by Thomson Reuters, uses output metrics and citation impact factors as a sole indicator of the state of national research systems. The reports are designed to "inform policymakers and others about the landscape and dynamics of the global research base" and at the global level, they aim to "help provide a further context to that set by the OECD's economic reports, while also furnishing background against which to view the pertinent regional dispatches in the UNESCO Science report 2010." ${ }^{25}$

\section{Implications for Local Research and Development}

These metrics "can have perverse and dangerous effects on universities in underdeveloped countries in the global South," Saleem Badat argues. ${ }^{26}$ In the place of "uncritical mimicry and 'catching up' with the world class university," which relegates developing country research systems to second-rate status in an idealized global hierarchical system, he argues for the creation of favorable national environments for universities' contribution to society. What is needed, if research is truly to have an impact on social development in the developing world, is a diversity of models and of measures aligned to the realities of a diversity of university systems across the world. ${ }^{27}$

The impact of the wide adoption of this system of evaluation is to render invisible wide swathes of developing country research, and to distort the emergence of knowledge production that serves local development needs. While the journals included in the ISI indexes are only a very small proportion of the publications emerging from developing countries, the publications not included are consigned to oblivion, with very small circulation, little reach beyond the borders of the country of publication, and minimal impact in the global research system. ${ }^{28}$ Typically, as the South African Academy of Science discovered, local print journals had a circulation of under four hundred. ${ }^{29}$ Moreover, the assumption that locally produced 
publications in developing countries are of lower quality can become a self-fulfilling prophecy, as researchers from peripheral countries focus their energies on conforming to the requirements of Global Northern journals for the sake of their prospects of recognition and advancement in an idealized global system. ${ }^{30}$

Jean-Claude Guédon argues that as researchers try to achieve their visibility in global journals "the end result is a paradoxical and unexpected form of foreign 'contribution' or aid flowing from poor countries to rich countries." ${ }^{31}$ In the political economy of global knowledge production, this tends to go unnoticed by governments and international agencies; they adopt impact factors as the norm for the monitoring of the research systems that they oversee, while at the same time questioning why their research systems are not more responsive to urgent development needs in their regions. ${ }^{32}$

The system, in turn, involves a distortion of research priorities, as researchers seek exposure in international journals, often in contradiction to their own reasons for conducting research ${ }^{33}$ and of the research priorities in their region. This has resulted, worldwide, in an emphasis, for example, on research dealing with health issues that are of concern to the United States and Europe and that have economic potential in these markets.

Thus Benkler argues that in the last decade, more attention has been paid to research on curing acne than on malaria. ${ }^{34}$ The research system also favors disciplinary production over area studies, while applied disciplines like engineering and agriculture are less well represented. ${ }^{35}$

As a result, social science research of importance to national and regional policy and economic development, health research on neglected diseases that affect the developing world, or agricultural research relevant to food sustainability, are marginalized and under-published. ${ }^{36}$

\section{Limits of Open Access $\mathbf{1 . 0}$ as an Alternative Paradigm}

In this context Open Access becomes critically important as a way of leveling the playing field and providing a voice for developing country publications. Open Access has emerged as an alternative paradigm to address these concerns. OA refers to online access to scholarly literature that is free from price and most permission barriers. The primary target of OA is the peerreviewed journal literature, but other research related outputs, including data, software, research reports, and monographs are also being considered. The impetus for OA is that it "gives authors and their works vast and measurable new visibility, readership, and impact." ${ }^{37}$

Two broad approaches have developed in the scholarly community for the use of open access to maximize research exposure and impact. One is 
to use the potential of open access repositories, institutional or subjectbased, in order to provide access to the text of articles published in closed access journals. The posting of preprints (the article before peer review) or postprints (the text revised after peer review but before editing and typesetting) is allowed by a high percentage of journal publishers. This has come to be known as author self-archiving or the "green route" and is promoted by some advocates as the only effective way to get maximum benefit from Open Access while still benefiting from the skills of professional publishers. ${ }^{38}$ The use of these institutional repositories has demonstrated considerably increased downloads and increased citations over time. ${ }^{39}$

The other approach, the "gold route," to Open Access is the publication of journals, using a variety of business models. There are now close to nine thousand such journals listed in the major OA journal directory and over one million full text articles. ${ }^{40}$ Open Access journals have seen considerable growth in numbers of journals and even higher growth in numbers of articles, in comparison with subscription journals. ${ }^{41}$ Early adopters were in the medical and biological sciences: the Public Library of Science (PLOS) as a not-for-profit publisher produces eight broad-based disciplinary journals, and BioMedCentral, now owned by Springer Science+Business Media, is a commercial open access publisher that now publishes hundreds of OA titles based on the authors-pay model of gold OA publishing. These publishers have been quick to point to the impressive citations counts of articles published in their journals, and the rapid rise in JIF of their flagship journals. In essence, they are still using the same yardstick to measure research quality and impact. Numerous studies have now been published on the citation advantage of OA, either through the green or the gold route. ${ }^{42}$

The gold route has a particular appeal in the developing world, which experiences barriers to the effective distribution of research publications. The Academy of Science of South Africa (AASAf), for example, has argued that there is a need to use Open Access as the publication route for journal articles (and books) in order to provide a platform that will grow the volume of research out of the Global South and ensure its wide dissemination. ${ }^{43}$ ASSAf, supported by the South African government, has joined the Scientific Library Online (SciELO) platform in Brazil, a large regional platform for the hosting of Latin American publications. ${ }^{44}$

Unfortunately, however, debates over which of these two routes is better often tend to miss out on the bigger question of how best, in a network society, to produce knowledge that addresses the problems of development. As long as the journal article and the scholarly monograph remain the currency of international scholarship, the current hierarchies that limit the 
potential of developing country research and of research for development will continue. As Nancy L. Maron and K. Kirby Smith argue:

The urge to consider new forms in comparison to the monograph and journal genres that dominate library collections and the consciousness of the Academy is powerful. Yet this frame for interpreting changing practises of scholarly communication carries the risk of falling into a certain circularity of thought-we may acknowledge that scholarly works will change and yet behave as if anything that does not look like a traditional work of scholarship is not a scholarly work; thus the immutability of traditional publishing models becomes axiomatic. Different becomes less by definition. ${ }^{45}$

Cameron Neylon, writing about what scholarly communication would look like if it were invented now in the current digital age, argues that an anachronistic focus on the journal article is limiting the potential impact of research ${ }^{46}$ :

It is on re-usability and replication where our current system really falls down. Access and rights are a big issue here, but ones that we are gradually pushing back. The real issues are much more fundamental. It is essentially assumed, in my experience, by most researchers that a paper will not contain sufficient information to replicate an experiment or analysis. Just consider that. Our primary means of communication, in a philosophical system that rests almost entirely on reproducibility, does not enable even simple replication of results. A lot of this is down to the boundaries created by the mindset of a printed multi-page article. Mechanisms to publish methods, detailed laboratory records, or software are limited, often leading to a lack of care in keeping and annotating such records. After all if it isn't going in the paper why bother looking after it?

The resulting impact is described in a study commissioned by the Southern African Regional Universities Association (SARUA). The study's authors argue that the current framework for academic publishing, with its low valuation of local publishing and its exclusion of gray literature from recognition and reward systems, contributes to low publication rates. More damaging, the report found that there was limited access to research publications across the region, limiting the potential for collaborative research and leading to inefficiencies and research duplication. ${ }^{47}$

We must ask, however, whether the problem is what is being produced, or what is being measured. We would argue that developing countries are producing knowledge, and the problem is increasingly one of what is being measured. While this production is perhaps not in large volumes, it is certain that the hidden research production is far larger and more significant than that published in journal articles. What sort of a publication, metrics and rewards system can ensure that this knowledge is made available to the widest audience possible, in ways that support development efforts? 


\section{OA 2.0 and Experiments in Alternative Metrics}

In recent years we have seen a proliferation of scholarly metrics, many indeed designed to take advantage of the OA environment and to provide alternative to the JIF. ${ }^{48}$ The rationale is that better tools that are easy for scholars to use will form part of the OA toolkit and further drives the uptake of OA. The eigenfactor developed by Carl Bergstrom, ${ }^{49}$ which employs Google-like page rank indices to refine citation ranking; the refinement of usage and download metrics from repositories ${ }^{50}$; and the use of recommender and rating systems by PLoS ONE ${ }^{51}$ are all welcome developments.

While these new metrics are an improvement over the JIF, such as the longer window of citation and multiple data sources, these measures do not really extend beyond the literature and into the dynamic nature of the research life cycle and the diverse forms of scholarly communications that are taking place. In essence, the journal article in its final form is still being treated by conventional publishers as a static object to be counted, rather than a dynamic artifact at a specific stage in the knowledge production and dissemination cycle. What remains to be developed are tools that capture the multiple benefits at various stages of the research knowledge life cycle and the recognition mechanisms that recognize these multiple benefits, not only at the publication stage, but also during the research process (for example new protocols, data generation, community engagement, and postpublication review).

Happily, we are witnessing an expansion of the ethos of OA to a broadened conception of openness in scientific research and scholarly practices. Beyond citation impact, researchers are beginning to document the multiple benefits of more open practices to research and their dissemination. What we are seeing, in effect, is a merging of open access with open research approaches.

A recent study by the United Kingdom-based Research Information Network $^{52}$ found a number of distinct benefits of openness reported by researchers, such as the increased efficiency of research through lower costs of data collection, avoidance of duplication of effort, and sharing of protocols and best practices. Some researchers reported that making methodologies and protocols open for comments and scrutiny led to more rigorous and higher quality of research. Others noted that reuse of data and other material created by other researchers led to new research questions and new ways of engaging existing questions with new data. In particular, the open access to government data in the United Kingdom has allowed epidemiologists to reuse the data in ways that had direct impact on health policy. 
Openness has also led to enhanced collaboration and community building. At the same time the enhanced visibility of research leads to new opportunities for much wider engagement, not only across research communities, but also with the broader public in the form of citizen science and public engagement with the process and result of research. Researchers are also using a variety of social media, from initial proposal writing, to data gathering, to publishing and subsequent knowledge mobilization and knowledge translation after formal publication.

A growing number of researchers are experimenting with new forms of publishing. The traditional scientific paper is being deconstructed; an article may be published as a composite of modules, which allows the data, analysis tools, protocols, interpretations, multimedia objects, and supplementary materials to be made available in whole and in parts. These components can also be cited and linked in multiple ways. ${ }^{53}$ An author or research group can be cited and given credit for the data made available, or for providing the software tools, or for their interpretation of the data or the subject.

Web 2.0 and semantic mark-up tools now exist that allow for easy implementation of the modular structure of new publications; this may lead to a more fine-grained articulation of the original contributions to knowledge and provide better resolution to authorship and attribution. An example is WikiDashboard, ${ }^{54}$ a social dynamic analysis tool for Wikipedia intended to keep track of the contributions by dispersed writers. It is easy to imagine how such a tool could be adapted for credit and reputation attribution in open collaborative research.

Jason Priem and Bradley M. Hemminger compiled and reviewed a growing list of Web 2.0 applications that they grouped into seven categories: "bookmarking, reference managers, recommendation services, comments on articles, microblogging, Wikipedia, and blogging." ${ }^{55}$ They pointed out that as researchers increasingly adopt these tools for scholarly purpose, the usage and socially generated data gathered by these tools could be harnessed for building services for "scientometrics 2.0."

But managing the proliferation of data and more metrics is a daunting task, and making sense of these diverse sources would be even more challenging. A key constraint for researchers is time, and services that integrate these diverse tools into the researchers' workflow will be more attractive to busy researchers. Given the early stage of such development, however, the key question of whether these tools will bring the appropriate recognition for researchers remains to be answered. As Neylon has argued, technology solutions are available, as are the licenses, to enable OA. More intractable, however, are issues of research culture. 


\section{Open Access 2.0 and the Developing World}

Whether Web 2.0 platforms can be harnessed for publishing and dissemination of research from the Global South is an area that is not well researched. This is a significant question, as a large percentage of research conducted in the developing world by local researchers does not make it to the formal publication stage for a variety of reasons. The academic reward and promotion system, which rewards journal articles as the required publication output, fails to recognize the successive transformations of the university's relationship with civil society and industry over the twentieth century and hence the realities of research production. Arguing for increased funding and recognition of use-inspired research in South African universities, David Cooper suggests that this would form part of a necessary realignment with current realities: "[A] national position needs to be articulated ... that in the knowledge society of the third industrial revolution, issues of health, housing, transport, etc., are not independent of university research efforts. In fact, university research . . . should directly seek to provide knowledge for the alleviation of such social problems and hence for the condition of poverty of the majority of our population." ${ }^{15}$

This would lead, according to Cooper, to the inclusion, in recognition and reward systems, of the policy and development-oriented publications that were being produced in the research groupings he studied. This concurs with the findings of a study of research communication at the University of Cape Town's Opening Scholarship program, ${ }^{58}$ which identified a culture of "translational" scholarship, or what Cooper calls "use-inspired basic research," ${ }^{59}$ in a number of research groupings. These produced, alongside traditional peer-reviewed articles, a range of publications, many of which were posted online on departmental websites, targeting increased impact among policymakers and communities.

In other cases, research of this kind is simply not communicated at all. For example, researchers in Ugandan public universities and research institutions gather data in many areas, such as public health, crop yield, and water quality. But often these data are not analyzed and synthesized due to a lack of funding or appropriate methodologies or analytic tools, and researchers may not have the training or language facility to write up research for formal publication. ${ }^{60}$ A good deal of valuable data, therefore, has been languishing in back rooms, often forgotten, resulting in duplication of research. Across Africa, this scenario is being played out repeatedly, contributing to the lack of local knowledge bases needed for solving local problems.

Many policymakers are not aware of the benefits of OA and open science, and most are not familiar with social media and their potential usage 
for science dissemination. There is a clear need to raise greater awareness, not only in support for capacity building for local research, but also for the use of new tools for dissemination, engagement, assessment, and recognition, while not simply duplicating the power structure of the Global North. At a practical level, one can imagine digital repositories being set up for researchers to upload and store their research materials, including data, draft papers, preprints, research reports, theses, proposals as well as postprints. Support for social networking tools could enhance research collaboration across national boundaries.

Platforms such as AuthorAid, ${ }^{61}$ set up by the International Network for the Availability of Scientific Publications (INASP), are laudable experiments in using Web 2.0 to build scientific capacity in the Global South. The site is essentially a social networking platform that allows established researchers to serve as mentors for less-experienced researchers. But additional tools are required, such as repositories, and they should be integrated into the same platform to create collaborative spaces for knowledge development and sharing.

This expanded concept of research communication could also help support more effectively the variety of communicative efforts that African researchers are undertaking in their search for the impact their research can have on development goals. For example, in one of the author's video interviews with a Kenyan crop scientist, Professor Mary Abukutsa-Onyango, ${ }^{62}$ the professor discusses the challenges she faced when trying to publish her original research on African Indigenous Vegetables (AIV) in international journals, and notes the importance of OA journals in Africa to ensure that important research relevant to the continent is being published, read, and applied. She also discusses the potential impact that the dissemination of her work (particularly through translated literature in the form of simplified pamphlets to the farmers and policymakers) can have on poverty reduction, improvements in nutrition, agricultural development, and environmental sustainability. She also hints at the wider potential for capability development and the reinforcement of cultural values, which she sees as part and partial of development for countries like Kenya.

It is unlikely that the kinds of impact noted could be easily recorded by existing 2.0 tools, nor is it clear at this stage how metrics can be created to better reflect these uncaptured impacts. But it is important to gather examples such as the research done by Abukutsa-Onyango and to build awareness of the issues and possibilities, to follow the multiple impacts through, and attempt, as far as possible, to measure those impacts and provide a more persuasive policy rationale for research funders and governments. 
Such an approach would hopefully enable policymakers to reach betterinformed decisions, provide support for the development of access and dissemination policies, and have an effect on assessment initiatives outside the narrow framework of citation metrics.

\section{Policy Alignment}

The question then, is how to convince researchers and policymakers alike to take up OA 2.0 as the guiding approach to research metrics. Some proponents of OA see the higher citation impact as a key incentive for authors and assume that this alone would be sufficient to drive the widespread adoption of OA. ${ }^{63}$ Economic arguments for better return on research investment have also been made, promoting the idea that funders should therefore favor OA given their interest in seeing the greater impact of the research they fund. ${ }^{64}$ But a decade of experimentation with author self-archiving of published papers has shown that left to OA proponents' own initiative, self-archiving rate has hovered around 10 percent to 15 percent for most institutions. This has led some key proponents of OA to advocate for funding and policy mandates in order to propel higher uptake of OA.

It has not been fully acknowledged, however, that these arguments have tended to focus on the leverage of the traditionally accepted publication outputs-formally published journal articles and scholarly books. This narrower vision, this chapter has argued, fails to engage fully with the transformation of research practice in the postwar development of the knowledge economy as well as with the fundamental transformations in communications in the twenty-first-century networked society. Openness generates a host of benefits, and policy needs to reflect the values of these benefits so that researchers are encouraged to embrace them and further amplify them. Institutions and funders need to balance the value placed on the agency (the process and interactions), rather than simply on the output and quantity of research. ${ }^{65}$

In many countries affiliated with the Organisation for Economic Cooperation and Development (OECD), public funders are beginning to place stronger emphasis on the importance of social engagement, public dialogue, knowledge translation, and mobilization as part and parcel of the research life cycle. ${ }^{66}$ In countries like Canada, funding is being made available for knowledge translation projects in order to maximize the multiple impacts of research, in public health and in other areas of the social sciences. ${ }^{67}$ It may well be the case that if funder policy encouraging social engagement were to be aligned with policy on OA, we may see an increased uptake of both by scientists and a cascade of possible benefits as a result. 
At the same time, universities need to revisit the primary mission of knowledge creation and stewardship, and place stronger emphasis on the scholarship of engagement, which "means connecting the rich resources of the university to our most pressing social, civic and ethical problems, to our children, to our schools, to our teachers and to our cities." ${ }^{68}$ Indeed the reputation of an institution should be tied to the degree of such engagement, not simply ranking on some international scale based largely on citation impact.

Blade Nzimande, Minister of Higher Education and Training in South Africa, has called for a change in the prevailing ranking system: "Our universities, in particular, should be directing their research focus to address the development and social needs of our communities. The impact of their research should be measured by how much difference it makes to the needs of our communities, rather than by just how many international citations researchers receive in their publications." ${ }^{69}$

Many South African academics are doing what Nzimande advocates, but the policy administered by his department (DHET) and driven by the often conservative senior echelons of the universities still often blocks the full acknowledgment of and reward for much of the research being done. If South African and African research is really to contribute to regional development goals, as the policymakers constantly request, this will need to change. The whole suite of research output will have to be taken into account, beyond the narrow field of journal articles, monographs, and books.

At the same time, new types of data that correspond to the commitment above have to be collected for generating a new metrics, and new kinds of accounting based on social accounting principles that measure multiple values would have to be employed to generate the reputation of such new metrics. A starting point is to expand the vocabulary on impact to include other kinds of success, value, and capital and to recognize that depending on the kind of value we wish to emphasize, we will need to employ the appropriate or correspondent metrics. Metrics, in other words, should serve to support what we value, and not define it. The narrow focus of the journal impact factor as the one-size-fits-all metric for valuing scholarship has had a damaging influence in obscuring the realities of twenty-first-century research, particularly in the developing world, impeding the implementation of the development focus that the policymakers seek.

\section{Conclusion}

We live in a time when some of the most pressing problems of humanity are transnational and global in nature. The solution to these problems, 
such as the growing inequality in health and wealth, and the many negative consequences of climate change, requires a substantial involvement by the public sector and new kinds of thinking centered on nonmarket-based peer production of knowledge. The deep negative effect of the current global recession draws sharp attention to the failures of neoliberal economic theories based on the power of market and growth. It serves as a critical reminder that there is a pressing need to redefine the values that underpin recognition and reward systems for universities, their researchers, and their outputsand to align them with public good and development goals.

Decision makers, funding agencies, faculty members, and researchers have the responsibility to learn about the value of different emerging metrics, and not to rely solely on commercial providers to dictate the terms of evaluation. Currently we have a highly dysfunctional scholarly communication system, especially in the sciences, where both the means of publishing and the means of evaluation are controlled by private for-profit entities that are not accountable to the public. The OA movement has in part exposed some of this structural imbalance.

The scholarly community has the means and the tools to correct this situation and to bring research back in line for the public interest. Now is the opportune time for stakeholders in the scholarly communication system to work collaboratively toward a new set of tools and policies that reframe scholarship and knowledge in terms of the diversity of processes and research impact.

While we have seen a proliferation of metrics for measuring productivity, so far the rankings of universities have not been particularly good at valuing their roles in social responsibility, environmental sustainability, and community engagement. It is time to produce a new kind of reputation ranking based on the institution's contribution to the public good and their commitment to a global knowledge commons. This will ultimately serve to overcome Benkler's divide between neoliberal informational economy and the cultural ethos of the network society.

\section{Notes}

1. M. Laakso et al., "The Development of Open Access Journal Publishing from 1993 to 2009," PLoS ONE 6, no. 6 (2011): e20961, doi:10.1371/journal.pone.0020961; R. Poynder, "Open Access by Numbers. Open and Shut," 2011, http://poynder .blogspot.ca/2011/06/open-access-by-numbers.html; see also "The Global OA Map," http://openaccessmap.org. 
2. L. Carr, A. Swan, and S. Harnad, "Creating and Curating the Cognitive Commons: Southampton's Contribution," in Curating the European University, ed. M. Simons, M. Decuvpere, J. Vlieghe, and J. Masschelein (Leuven, BE: Universitaire Pers Leuven, 2011), 193-199, http://eprints.soton.ac.uk/271844.

3. L. Chan and S. Costa, "Participation in the Global Knowledge Commons: Challenges and Opportunities for Research Dissemination in Developing Countries," New Library World 106, no. 3/4 (2005): 141-163 https://tspace.library.utoronto.ca/ bitstream/1807/2388/2/chan_costa.pdf; N. Boshoff, "South-South Research Collaboration of Countries in the Southern African Development Community (SADC)," Scientometrics 84 , no. 2 (2010): 481-503.

4. The Prime Minister of Namibia, Nahas Angula, speaking at the 2009 World Conference on Higher Education, in the Round Table on African Higher Education. Quoted in E. Reddon "An Academic Revolution," Inside Higher Ed, November 22, 2009, http://www.insidehighered.com/news/2009/07/07/unesco.

5. As the result of a number of factors, including the marketization of universities and demands for numeric measures to measure efficiency and outputs, the Thompson Reuters journal impact factor has, over the last fifty years, become the single most dominant measure for research effectiveness, being used to measure national levels of research publication effectiveness in documents such as the UNESCO World Science Report. See B. D. Cameron, "Trends in the Usage of ISI Bibliometric Data: Uses, Abuses, and Implications," Libraries and the Academy 5, no. 1 (2005): 105-125; and É. Archambault, and V. Larivière "History of Journal Impact Factor: Contingencies and Consequences, Scientometrics 79, no. 3 (2009): 639-653.

6. S. Arunachalam, "The Global Research Village: A View from the Periphery," Digital Library of Information Science and Technology, http://arizona.openrepository.com/ arizona/handle/10150/105067; L. Velho, "The "Meaning" of Citation in the Context of a Scientifically Peripheral Country," Scientometrics 9, no. 1-2 (1986): 71-89.

7. V. Archambault and E. Larivière, "The Limits of Bibliometrics for the Analysis of the Social Science and Humanities literature," in UNESCO World Social Science Report: Knowledge Divides (Paris: UNESCO Publishing and International Social Science Council, 2010): 251-254; E. Hazelkorn, "Pros and Cons of Research Assessment," in UNESCO World Social Science Report: Knowledge Divides (Paris: UNESCO Publishing and International Social Science Council, 2010): 255-258. http://unesdoc.unesco .org/images/0018/001883/188333e.pdf.

8. M. Castells, The Rise of the Network Society (Malden, MA: Blackwell Publishers, 2000).

9. Y. Benkler, The Wealth of Networks: How Social Production Transforms Markets and Freedom (New Haven, CT: Yale University Press, 2007). 
10. See, for example, C. Neylon and S. Wu, "Article-Level Metrics and the Evolution of Scientific Impact," PLoS Biology7, no. 11 (November 2009): e1000242, http:// dx.plos.org/ambra-doi-resolver/10.1371/journal.pbio.1000242; see also Neylon's blog, Science in the Open, http://cameronneylon.net, where alternative metrics are extensively discussed and J. Priem, "Altmetrics: A Manifesto," 2010, http://www .altmetrics.org.

11. Y. Benkler, "The Idea of Access to Knowledge and the Information Commons: Long-term Trends and Basic Elements," in Access to Knowledge in the Age of Intellectual Property, ed. G. Krikorian and A. Kapczynski (New York: Zone Press, 2010): 217.

12. UNESCO, Toward Knowledge Societies: UNESCO World Report (Paris: UNESCO Publishing, 2005), http://unesdoc.unesco.org/images/0014/001418/141843e.pdf; D. Bloom, D. Canning, and K. Chan, Higher Education and Economic Development in Africa (Washington, D.C.: World Bank, 2005), http://ent.arp.harvard.edu/ AfricaHigherEducation/Reports/BloomAndCanning.pdf.

13. A ten-year partnership program among the Association of Commonwealth Universities (ACU), the Association of African Universities (AAU), and Higher Education South Africa (HESA).

14. Benkler, "The Idea of Access," 223.

15. C. S. Wagner, The New Invisible College: Science for Development, (Washington, D. C.: Brookings Institution Press, 2008).

16. Benkler, "The Idea of Access," 220-221.

17. P. Drahos and J. Briathwaite, Information Feudalism: Who Owns the Knowledge Economy? (New York: New Press, 2003).

18. UNESCO, UNESCO Science Report 2010: The Current Status of Science Around the World, (Paris: UNESCO Publishing, 2010).

19. B. D. Cameron "Trends in the Usage of ISI Bibliometric Data: Uses, Abuses, and Implications," Libraries and the Academy 5, no. 1 (2005): 105-125; A. Paasi, "Globalisation, Academic Capitalism, and the Uneven Geographies of International Journal Publishing Spaces," Environment and Planning 37, no. 5 (2005): 769-789; C. Merrett, "The Expropriation of Intellectual Capital and the Political Economy of International Academic Publishing," Critical Arts: A Journal of South-North Cultural and Media Studies 20, no. 1 (2006): 96-111.

20. UNESCO, World Social Science Report, 248-261.

21. A. S. Canagarajah, The Geopolitics of Academic Writing (Pittsburgh, PA: University of Pittsburgh, 2002).

22. D. King, "The Scientific Impact of Nation," Nature 430, (2004): 311-316, http:// www.nature.com/nature/journal/v430/n6997/full/430311a.html. 
23. J. Guédon, "Open Access and the Divide Between 'Mainstream' and 'Peripheral' Science," in Como gerir e qualificar revistas científicas (in English translation), http:// eprints.rclis.org/10778/1/Brazil-final.pdf.

24. See http://www.worldmapper.org/display.php?selected=205. The authors have been granted permission to reproduce this figure under the terms of the Creative Commons Attribution License, which permits unrestricted use, distribution, and reproduction in any medium, provided the original author and source are credited. Source of data used to create map: World Bank's 2005 World Development Indicators.

25. J. Adams, C. King, and D. Hook, Global Research Report: Africa (Leeds: Thomson Reuters, 2010), 8, http://thomsonreuters.com/content/corporate/docs/globalresearch report-africa.pdf.

26. S. Badat, "The World-Class University and the Global South," in UNESCO World Social Science Report: Knowledge Divides (Paris: UNESCO Publishing and International Social Science Council, 2010): 246.

27. Ibid.

28. L. Chan, B. Kirsop, and S. Arunachalam, "Open Access Archiving: The Fast Track to Building Research Capacity in Developing Countries," (London: SciDev.Net., 2005), http://www.scidev.net/en/features/open-access-archiving-the-fast-track-to -building-r.html; L. Chan, B. Kirsop, and S. Arunachalam, "Towards Open and Equitable Access to Research and Knowledge for Development," PLoS Med 8, no. 3 (2011): e1001016. http://www.plosmedicine.org/article/info:doi/10.1371/journal .pmed.1001016.

29. W. Gevers and X. Mati, eds. Report on a Strategic Approach to Research Publishing in South Africa (Pretoria: Academy of Science of South Africa, 2006): 75-77, http://www.assaf.co.za/wp-content/uploads/reports/evidence_based/assaf_strategic _research_publishing.pdf.

30. Badat, "The World-Class," 246-247.

31. Guédon, "Open Access," 9.

32. E. Gray, "Access to Africa's Knowledge: Publishing Development Research and Measuring Value," African Journal of Information and Communication. Special issue on Scholarly Communication and Access to Information, edited by Luci Abrahams and Eve Gray, 2010, 4-19, http://link.wits.ac.za/journal/AJIC10-Gray.pdf.

33. J. Mouton et al., "The State of Public Science in the SADC Region," in Toward a Common Future: Higher Education in the SADC Region: Research Findings from Four SARUA Studies, Study Series 2008, ed. P. Kotecha (Johannesburg: SARUA, 2008), 199-302, http://www.sarua.org/files/publications/TACF/Chapter4_full.pdf.

34. Benkler, The Wealth of Networks, 303. 
35. Gevers and Mati, Report on a Strategic Approach, 75-77; UNESCO, World Social Science Report, 253.

36. Benkler, "The Idea of Access," 329-344.

37. The Budapest Open Access Initiative, http://www.opensocietyfoundations.org/ openaccess/read.

38. S. Harnad et al., "The Access/Impact Problem and the Green and Gold Roads to Open Access: An Update," Serials Review 34, no. 1 (2008): 36-40.

39. A. Swan, "The Open Access Citation Advantage: Studies and Results to Date," February, 2010, ECS EPrints.

40. Directory of Open Access Journals, http://www.doaj.org (information from November 1, 2011).

41. B.-C. Björk et al,"Open Access to the Scientific Journal Literature: Situation 2009," PLoS ONE 5, no. 6 (2010): e11273, doi:10.1371/journal.pone.0e011273, http://www.plosone.org/article/citationList.action?articleURI=info\%3Adoi\%2F10.13 71\%2Fjournal.pone.0011273.

42. Y. Gargouri et al., "Self-Selected or Mandated, Open Access Increases Citation Impact for Higher Quality Research," PLoS ONE 5, no. 10 (2010): e13636. http:// www.plosone.org/article/info\%3Adoi\%2F10.1371\%2Fjournal.pone.0013636.

43. Gevers and Mati, Report on a Strategic Approach, 75-77.

44. Scientific Electronic Library Online, http://www.scielo.org./php/index.php.

45. N. L. Maron and K. K. Smith, Current Models of Digital Scholarly Communication: Results of an Investigation Conducted by Ithaka for the Association of Research Libraries, (Washington, DC: ARL, 2008): 6.

46. C. Neylon, "What Would Scholarly Communications Look Like if We Invented it Today?," Blog posting, Science in the Open, 2010, http://cameronneylon.net/blog/ what-would-scholarly-communications-look-like-if-we-invented-it-today/.

47. L. Abrahams et al., "Opening Access to Knowledge in Southern African Universities," in SARUA Study Series (Johannesburg: Southern African Regional Universities Association, 2008), http://www.sarua.org/?q=publications/opening-access -knowledge-southern-african-universities.

48. M. A. Banks and R. Dellavalle, "Emerging alternatives to the impact factor," OCLC Systems \& Services 24, no. 3 (2008): 167-173, doi:10.1108/10650750810898200; J. Bollen et al., "A Principal Component Analysis of 39 Scientific Impact Measures," PLoS ONE 4 no. 6 (2009): e6022, doi:10.1371/journal.pone.0006022.

49. C. T. Bergstrom, J. D. West and M. A. Wiseman, "The Eigenfactor ${ }^{\mathrm{TM}}$ Metrics," The Journal of Neuroscience 28, no. 45 (2008): 11433-11434, doi:10.1523/JNEUROSCI.0003-08.2008. 
50. T. Brody et al., "Incentivizing the Open Access Research Web: PublicationArchiving, Data-Archiving and Scientometrics," CTWatch Quarterly 3, no. 3 (2007).

51. PLoSOne, is built on the separation of scientific rigor and impact. The former is reviewed before publication, the latter only after publication. PLoSOne is growing exponentially and is being emulated by a number of the big journal publishers. The prediction is that this model of megajournal could account for 50 percent of the literature by 2016. A variety of new impact factors-beyond the citation count-are being explored and the value of the content is being enhanced through the creation of social networking hubs. Mark Patterson described this in a paper, "Re-engineering the Functions of Journals," at the CERN 2011 Workshop on Innovations in Scholarly Communications (A17), 2011, https://indico.cern.ch/contributionDisplay.py ?sessionId=8\&contribId=20\&confId $=103325$.

52. "Open Science Case Studies," Research Information Network UK, 2010, http:// www.dcc.ac.uk/projects/open-science-case-studies.

53. A. de Waard and J. Kircz, "Modeling Scientific Discourse-Shifting Perspectives and Persistent Issues," in ELPUB2008. Open Scholarship: Authority, Community, and Sustainability in the Age of Web 2.0, Proceedings of the 12th International Conference on Electronic Publishing, ed. L. Chan and S. Mornati, Toronto, Canada, June 25-27, 2008, 234-245.

54. http://wikidashboard.appspot.com.

55. J. Priem and B. Hemminger, "Scientometrics 2.0: Toward New Metrics of Scholarly Impact on the Social Web," First Monday 15 no. 7 (2010), http://www.uic.edu/ htbin/cgiwrap/bin/ojs/index.php/fm/article/view/2874/2570.

56. Ibid.

57. D. Cooper, The University in Development: Case Studies of Use-Oriented Research (Pretoria: HSRC Press, 2011): 329, http://www.hsrcpress.ac.za/product.php?productid $=2286 \&$ freedownload $=1$.

58. Opening Scholarship, http://www.cet.uct.ac.za/OpeningScholarship.

59. Cooper, The University in Development, 2011.

60. P. Nampala, see interview: http://vimeo.com/15370013.

61. AuthorAid, http://www.authoraid.info.

62. M. Abukutsa-Onyango, interview by L. Chan, February 10, 2010, http://vimeo .com/10169351.

63. S. Harnad, "Waking OA's 'Slumbering Giant': The University's Mandate to Mandate Open Access," New Review of Information Networking 14, (2008): 51-68.

64. J. Houghton et al., Economic Implications of Alternative Scholarly Publishing Models: Exploring the Costs and Benefits, London and Bristol: Joint Information Systems Com- 
mittee (JISC), 2009: J. W. Houghton and C. Oppenheim, "The Economic Implications of Alternative Publishing Models," Prometheus 28, (2010): 41-54.

65. M. Hall, "Minerva's Owl. A Response to John Houghton and Charles Oppenheim's 'The Economic Implications of Alternative Publishing Models,'" Prometheus 28, (2010): 61-71.

66. A. Kitson and S. E. Straus, "The Knowledge-to-action Cycle: Identifying the Gaps," Canadian Medical Association Journal 182, no. 2, (2010): E73-E77; Knowledge Translation at the Canadian Institutes of Health Research (n.d.), http://www.ncddr .org/kt/products/focus/focus 18 .

67. R. Landry et al., "The Knowledge-Value Chain: A Conceptual Framework for Knowledge Translation in Health," Bull World Health Organ [online] 84, no. 8 (2006): 597-602, http://www.scielosp.org/scielo.php?script=sci_arttext\&pid=\$0042-9686200 $6000800009 \& \operatorname{lng}=$ en $\&$ nrm=iso.

68. E. L. Boyer, "The Scholarship of Engagement," Bulletin of the American Academy of Arts and Sciences 49, no. 7 (1996): 32.

69. Speech delivered at the Women in Science Awards, Johannebsurg, August 21, 2009. Reported on the Department of Higher Education and Training website, http://www.dhet.gov.za.

\section{Bibliography}

Abrahams, L., M. Burke, E. Gray, and A. Rens. "Opening Access to Knowledge in Southern African Universities." SARUA Study Series. Johannesburg: Southern African Regional Universities Association, 2008. http://www.sarua.org/?q=content/ opening-access-knowledge-southern-african-universities.

Adams, J., C. King, and D. Hook. Global Research Report: Africa. Leeds, UK: Thomson Reuters, 2010. http://thomsonreuters.com/content/corporate/docs/globalresearchreport -africa.pdf.

Archambault, V., and E. Larivière. "The Limits of Bibliometrics for the Analysis of the Social Science and Humanities Literature." In 2010 World Social Science Report: Knowledge Divides. Paris: UNESCO Publishing and International Social Science Council, 2010: 251-254. Arunachalam, S. "The Global Research Village: A View from the Periphery." Digital Library of Information Science and Technology, http://arizona .openrepository.com/arizona/bitstream/10150/105377/1/Article_11.pdf.

Badat, S. The World-Class University and the Global South. In UNESCO World Social Science Report: Knowledge Divides, 245-246. Paris: UNESCO Publishing and International Social Science Council, 2010. 
Banks, M. A., and R. Dellavalle. "Emerging Alternatives to the Impact Factor." OCLC Systems \& Services 24 (3) (2008): 167-173. doi:10.1108/10650750810898200.

Benkler, Y. The Wealth of Networks: How Social Production Transforms Markets and Freedom. New Haven, CT: Yale University Press, 2007.

Benkler, Y. The Idea of Access to Knowledge and the Information Commons: Longterm Trends and Basic Elements. In Access to Knowledge in the Age of Intellectual Property, ed. G. Krikorian and A. Kapczynski, 217-236. New York: Zone Press, 2010.

Bergstrom, C. T., J. D. West, and M. A. Wiseman. "The Eigenfactor ${ }^{\mathrm{TM}}$ Metrics." Journal of Neuroscience 28 (45) (2008): 11433-11434. doi:10.1523/JNEUROSCI .0003-08.2008.

Björk, B.-C., P. Welling, M. Laakso, P. Majlender, T. Hedlund, and G. Gudnason. "Open Access to the Scientific Journal Literature: Situation 2009." PLoS ONE 5 (6) (2010): e11273. doi:10.1371/journal.pone.0011273 http://www.plosone.org/article/ citationList.action?articleURI=info\%3Adoi\%2F10.1371\%2Fjournal.pone.0011273.

Bloom, D., D. Canning, and K. Chan. Higher Education and Economic Development in Africa. Washington, DC: World Bank, 2005.

Bollen, J., H. Van de Sompel, A. Hagberg, and R. Chute. "A Principal Component Analysis of 39 Scientific Impact Measures." PLoS ONE 4 (6) (2009): e6022. doi:10.1371/journal.pone.0006022.

Boshoff, N. "South-South Research Collaboration of Countries in the Southern African Development Community (SADC)." Scientometrics 84 (2) (2010): 481-503.

Boyer, E. L. "The Scholarship of Engagement." Bulletin-American Academy of Arts and Sciences. American Academy of Arts and Sciences 49 (7) (1996): 18-33.

Brody, T., and L. Carr. Y. Gingras, C. Hajjem, S. Harnad, A. Stevan, A. Swan, L. Dirks, and T. Hey,. "Incentivizing the Open Access Research Web: Publication-Archiving, Data-Archiving and Scientometrics." CTWatch Quarterly 3 (3) (2007): 42-50.

Cameron, B. D. "Trends in the Usage of ISI Bibliometric Data: Uses, Abuses, and Implications." Libraries and the Academy 5 (1) (2005): 105-125.

Carr, L., A. Swan, and S. Harnad. "Creating and Curating the Cognitive Commons: Southampton's Contribution." In Curating the European University, edited by M. Simons, M. Decuvpere, J. Vlieghe, and J. Masschelein, 193-199. Leuven, Belgium: Universitaire Pers Leuven, 2011). http://redir.eprints.ecs.soton.ac.uk/redir .php?uri=/21844.

Castells, M. The Rise of the Network Society. Malden, MA: Blackwell Publishers, 2000.

Canagarajah, A. S. The Geopolitics of Academic Writing. Pittsburgh, PA: University of Pittsburgh, 2002. 
Chan, L., B. Kirsop, and S. Arunachalam. "Open access Archiving: The Fast Track to Building Research Capacity in Developing Countries." (London: SciDev.Net., 2005). http://www.scidev.net/en/features/open-access-archiving-the-fast-track-to-building -r.html.

Chan, L., and S. Costa. "Participation in the Global Knowledge Commons: Challenges and Opportunities for Research Dissemination in Developing Countries." New Library World 106 (3/4) (2005): 141-163. https://tspace.library.utoronto.ca/ bitstream/1807/2388/2/chan_costa.pdf.

Chan, L., B. Kirsop, and S. Arunachalam. "Towards Open and Equitable Access to Research and Knowledge for Development." PLoS Medicine 8 (3) (2011): e1001016. http://www.plosmedicine.org/article/info:doi/10.1371/journal.pmed.1001016.

Cooper, D. The University in Development: Case Studies of Use-Oriented Research. Pretoria: HSRC Press, 2011. http://www.hsrcpress.ac.za/product.php?productid=2286 \&freedownload $=1$.

De Waard, A., and J. Kircz. "Modeling Scientific Discourse-Shifting Perspectives and Persistent Issues." In ELPUB2008. Open Scholarship: Authority, Community, and Sustainability in the Age of Web 2.0, Proceedings of the 12th International Conference on Electronic Publishing, ed. L. Chan and S. Mornati, Toronto, Canada 25-27 June, 2008, 234-245.

Drahos, P., and J. Briathwaite. Information Feudalism: Who Owns the Knowledge Economy? New York: New Press, 2003.

Gargouri, Y., C. Hajjem, V. Lariviere, Y. Gingras, L. Carr, T. Brody, and S. Harnad. "Self-Selected or Mandated, Open Access Increases Citation Impact for Higher Quality Research." PLOS ONE 5 (10) (2010): e13636. http://www.plosone.org/article/ info\%3Adoi\%2F10.1371\%2Fjournal.pone.0013636.

Gray, E. "Access to Africa's Knowledge: Publishing Development Research and Measuring Value." African Journal of Information and Communication. Special Issue on Scholarly Communication and Access to Information, edited by Luci Abrahams and Eve Gray, 2010, 4-19, http://link.wits.ac.za/journal/AJIC10-Gray.pdf.

Gevers, W., and X. Mati eds. Report on a Strategic Approach to Research Publishing in South Africa. Pretoria: Academy of Science of South Africa, 2006: 75-77. http://ideas .repec.org/p/ess/wpaper/id706.html.

Guédon, J. "Open Access and the Divide Between "Mainstream" and "Peripheral" Science." In Como gerir e qualificar revistas científicas (in Portuguese). http://eprints .rclis.org/10760/10778/1/Brazil-final.pdf.

Hall, M. "Minerva's Owl. A Response to John Houghton and Charles Oppenheim's "The Economic Implications of Alternative Publishing Models.'" Prometheus 28 (2010): 61-71. 
Harnad, S., T. Brody, F. Vallières, L. Carr, S. Hitchcock, Y. Gingras, C. Oppenheim, and H. Stamerjohannes. "The Access/Impact Problem and the Green and Gold Roads to Open Access: An Update." Serials Review 34 (1) (2008): 36-40.

Harnad, S. "Waking OA's "Slumbering Giant": The University's Mandate To Mandate Open Access." New Review of Information Networking 14 (2008): 51-68.

Hazelkorn, E. "Pros and Cons of Research Assessment." In UNESCO World Social Science Report: Knowledge Divides. Paris: UNESCO Publishing and International Social Science Council, 2010: 255-258. http://arrow.dit.ie/cgi/viewcontent.cgi?article=1024 \&context=cserrep.

Houghton, J., B. Rasmussen, P. Sheehan, C. Oppenheim, A. Morris, C. Creaser, H. Greenwood, M. Summers, and A. Gourlay. Economic Implications of Alternative Scholarly Publishing Models: Exploring the Costs and Benefits. London and Bristol: Joint Information Systems Committee (JISC), 2009.

Houghton, J. W., and C. Oppenheim. "The Economic Implications of Alternative Publishing Models." Prometheus 28 (2010): 41-54.

King, D. "The Scientific Impact of Nation." Nature 430 (2004): 311-316. http://www .nature.com/nature/journal/v430/n6997/full/430311a.html.

Kitson, A., and S. E. Straus. "The Knowledge-to-Action Cycle: Identifying the Gaps." Canadian Medical Association Journal 182 (2) (2010): E73-E77.

Laakso, M., P. Welling, H. Bukvova, L. Nyman, B.-C. Björk, and T. Hedlund. "The Development of Open Access Journal Publishing from 1993 to 2009." PLoS ONE 6 (6) (2011): e20961.

Landry, R., N. Amara, A. Pablos-Mendes, R. Shademani, and I. Gold. "The Knowledge-value Chain: A Conceptual Framework for Knowledge Translation in Health." [online] Bulletin of the World Health Organization 84 (8) (2006): 597-602. http://www .scielosp.org/scielo.php?script=sci_arttext\&pid=S0042-96862006000800009\&lng=en $\& n r m=i s o$.

Maron, N. L., and K. K. Smith. Current Models of Digital Scholarly Communication: Results of an Investigation Conducted by Ithaka for the Association of Research Libraries. Washington, DC: ARL, 2008.

Merrett, C. "The Expropriation of Intellectual Capital and the Political Economyof International Academic Publishing." Critical Arts: A Journal of South-North Cultural and Media Studies 20 (1) (2006): 96-111.

Mouton, J., N. Boshoff, L. de Waal, and S. Esau. B, Imbayarwo, M. Ritter, and D. van Niekerk, "The State of Public Science in the SADC Region." In Towards a Common Future: Higher Education in the SADC Region: Research Findings from Four SARUA Studies, Study Series 2008, ed. P. Kotecha, 199-302. Johannesburg: SARUA, 2008. http:// www.sarua.org/files/publications/TACF/Chapter4_full.pdf. 
Paasi, A. "Globalisation, Academic Capitalism, and the Uneven Geographies of International Journal Publishing Spaces." Environment and Planning 37 (5) (2005): 769-789.

Priem, J., and B. M. Hemminger. "Scientometrics 2.0: Toward New Metrics of Scholarly Impact on the Social Web." First Monday 15 (7) (2010). http://www.uic.edu/ htbin/cgiwrap/bin/ojs/index.php/fm/article/view/2874/2570.

Reddon, E. "An Academic Revolution." Inside Higher Ed, November 22, 2009. http:// www.insidehighered.com/news/2009/07/07/unesco.

UNESCO. Towards Knowledge Societies: UNESCO World Report. Paris: UNESCO Publishing, 2005. http://unesdoc.unesco.org/images/0014/001418/141843e.pdf.

UNESCO. UNESCO Science Report 2010: The Current Status of Science Around the World. Paris: UNESCO Publishing, 2010. http://unesdoc.unesco.org/mages/0018/001899/ 189958e.pdf.

Velho, L. "The "Meaning" of Citation in the Context of a Scientifically Peripheral Country." Scientometrics 9 (1-2) (1986): 71-89.

Wagner, C. S. The New Invisible College: Science for Development. Washington, D.C.: Brookings Institution Press, 2008. 